\title{
Fandom, Music and Personal Relationships through Media: How Teenagers Use Social Networks
}

Pilar Lacasa

University of Alcalá, Madrid

p.lacasa@uah.es

\section{Laura Méndez Zaballos}

Universidad Nacional de Educación a Distancia, Madrid Imendez@psi.uned.es

\author{
Julián de la Fuente Prieto \\ University of Alcalá, Madrid \\ julian.fuente@uah.es
}

\begin{abstract}
This paper analyses the practices and products of the One Direction fan community, focusing on the interaction of adolescent girls with certain types of texts present on social networks. We examine how adolescents approach music celebrities when they participate in fandom online and offline communities, supported by online social networks that rely on the use of multimodal semiotic resources. We adopt an ethnographic perspective, mixing narrative and analytical interpretations, and seeking to overcome the contrasts between them. The following results are discussed: first, we examine how teens admire particular celebrities and turn them into heroes. They value positively the fact that celebrities have an offline life and exclude possible constructed celebrities only supported by virtual reality. Second, social networks become frames of
\end{abstract}


textual interpretation from which the meaning of multimodal texts are elaborated. Adolescent participation for building and understanding their heroes is related with different levels of activity, depending on their use of the Internet. Finally, girls move around fan communities in online and offline areas, both of them closely intertwined.

KEYWORDS: adolescents, social networks, music celebrities, community, multimodality

\section{Introduction}

Technology helps us to recreate the world, not only by inventing specific tools, but also by forming the environments in which people transmit information and knowledge. Apps now invite us to participate in social life; some emerge and others disappear, as mobile technology reinvents the communication channels that we use every day. Against this backdrop, we studied fandom, assuming the perspective taken in 1992 by Jenkins (2013) in his classic study of the topic. In his opinion, fandom works as an alternative social community whose members hold a set of practices in common that are associated with collective reception and the joint construction of meanings; members take an active stance and create their own culture. We also embrace Duffett's more recent definition: "Media fandom is the recognition of a positive, personal, relatively deep, emotional connection with a mediated element of popular culture" (Duffett, 2013: 2)

One Direction is an English-Irish pop boy band created in 2010 through the televised British singing competition The $X$ Factor. After five albums and several worldwide tours, the band temporarily split in January 2016. During their career, One Direction was propelled to international success by a remarkable spate of fan activity. The band's followers call themselves "Directioners" and use social media such as Twitter and Tumblr to promote both One Direction and its members. Directioners abide by several rules which are shared different communities around the world. Those who do not conform to these rules are considered "Directionators" and are not allowed to fully join One Direction fandom. The main rules are concern loving all the band members, and results in an overwhelming majority of female Directioners. Our article focuses on the practices and products of One Direction's fan community. We explore what the band represents by focusing on fan interaction around certain types of text circulating on social networks, by looking at both the online and offline lives of female fans.

Following pop bands is nothing new, but when fandom is mediated by social and digital media it becomes something more specific. The online fan community is broad, its sequence of interactions grows exponentially, and, above all, new forms of cultural production and creative activity emerge. Participants reinterpret the information which reaches everyone and this prompts a degree of collective further interpretation. From this perspective, we sought to answer three main questions. First, when adolescents participate in fan communities, how do they turn music celebrities into heroes? Second, how is collective imagination supported by social networks, distributed through the community, and developed around multimodal semiotic resources? Third, as adolescents pursue their fan 
practices in the Directioner community, how do their lives intertwine as part of a mutually unfolding online and offline world?

Our study is part of a large project exploring the use of new media by young people which aims to improve digital literacy. In this part, we observed and talked to five teenage Directioners about their participation in social networks. We argue that digital social media help to define adolescents' participation in the fan community. What follows is divided into three parts: first, a theoretical reflection; second, an empirical description of how the girls who participated in the research approached social networks. Finally, we look at the dimensions around which our main questions are structured.

\section{Towards a theoretical model}

\section{a) Teens and music celebrities: building a hero ${ }^{1}$}

Participating in a celebrity fan community involves organizing people in the network around an object: someone considered a "hero" with whom there is an emotional connection. Michailowsky (2014) suggests that people need heroes to obtain a reason to live whenever they cannot find one themselves. This is perhaps what sometimes happens during adolescence. We explore the role played by celebrities who are made into heroes within the fan community. It is clear that young people build their heroes through the information provided on social networks, where they interact with both the teams that manage the celebrities online presence and also with other fans. Looking at music celebrities, as this study does, Duffett (2014: 148) states - referring to Elvis - that the hero is more than a musician, he is a seducer, someone whose music is a vehicle for intimacy. Duffett speaks of "love", a feeling which is often mentioned in teenage fan communities. We wonder what it means to "love" a popular musician, someone who the fan has never seen. For Mark Duffett, "fan passion often seems an exceptional form of love, collectively expressed but open to change and review" (2014: 149), It is an emerging love without intimacy and can therefore be transformed by a certain knowledge of reality. It is love not so much for a person as for a performance; it is conditional love.

We will now look at how certain authors approach the processes through which the community constructs the representation of celebrities. Goffman's (1956) work on social presentation is an excellent starting point to explore how this representation is built in everyday life. Using his model, we might suggest that the information necessary for image management comes from three sources: first, the celebrity, who in turn becomes the object of representation for others. In the case of One Direction, it is clear that the band projects a certain online image, using both written and audiovisual languages. Second, someone's image depends on how the person is perceived by specific individuals who are close to them; in our case, fans who form small groups, providing proximity which helps to contribute to the creation of this image. Finally, Goffman refers to audiences, collective representations that are present in the fan community.

More recent studies allow us to specify further elements involved in the process of a celebrity becoming a hero. Barron (2014) recognizes that social media 
platforms, especially Twitter, have transformed the ways people approach celebrities because audience activities become texts that fans actively rebuild. These ideas are not new. Something similar occurred around the first cinema celebrities in Hollywood (DeCordova 1990). They place the emphasis on something that has already been analyzed in depth by Bakhtin and Holquist (1981), who allude to relationships between heroes built into texts created through dialogues between authors. New media contribute to such dialogues. Today, relationships are less distant than when communication was mainly unidirectional. People have become prominent conveyors of the events in a celebrity's public and private life. Such information is now retransmitted minute to minute (Marwick and Boyd 2011), but that is not all: celebrities' roles and activities are also reconstructed as stories. These narratives are also part of a material culture that turns them into objects. It is difficult to know to what extent they are independent of the marketing activities related to celebrities, of which young people are often unaware (Turner 2013). From this point of view, Baudrillard (2005) points out that celebrities become their own brand.

\title{
b) Teens' networked lives and fan communities
}

Communities involve participatory processes. In this article, we understand the fan community as a group of people who are aware of belonging to a group where they share values, goals and behaviours. In addition, it involves a common framework of interpretation and knowledge construction distributed among members. This definition is rooted in two complementary theoretical approaches proposed during the 1990s. First, over twenty years ago, Lave and Wenger (1991: 98) provided a concept of community that remains relevant:

\begin{abstract}
Nor does the term community imply necessarily co-presence, a well-defined, identifiable group, or socially visible boundaries. It does imply participation in an activity system about which participants share understandings concerning what they are doing and what that means in their lives and for their communities.
\end{abstract}

A few years later, from the perspective of socio-cultural psychology, Cole (1995) understood communities as activity systems: sets of actions, mediated by instruments, according to the rules accepted by the participants, that enable people to transform objects in order to achieve specific results. Today, mobile devices form the main instruments used by adolescents in fan communities. Devices such as smartphones have transformed the way in which people relate socially. Ling (2007) demonstrated several years ago that teens are, perhaps, the most consummate mobile telephone users. They coordinate at a global level, for example, as a fan community, and indeed micro-coordinate their personal interactions with each other by using specific apps. In addition to exchanging information, coordinating activities, or even asserting one's identity, it has been argued that mobile phones have an emancipatory function (Goggin and Hjorth 2014). We delve into how the practices related to them contribute to the development of the fan community. They make it easy to generate, interpret and distribute specific texts. Following Miller and Goodnow (1995: 7), we understand these activities as cultural practices: "they are actions that are 
repeated, shared with others in a social group, and invested with normative expectations and with meanings or significances that go beyond the immediate goals of the action".

In parallel to the developments in socio-cultural studies, in 1992 Henry Jenkins developed a second strand of thinking in his book Textual Poachers (2013). His understanding of fan communities connected fandom to collective intelligence, a concept firmly rooted in Pierre Lévy's (1997) theories. According to Jenkins, fan communities have long defined their membership through affinities rather than localities. They were "imagined" and "imagining" communities long before the introduction of networked computers. Such communities organized themselves around unrecognized forms of cultural production where the group was more important than any individuals. They arose from different texts that engaged people, not only rationally but also emotionally; where the power of information lies, among other things, in its capacity for circulation. The Internet allows for the formation of larger communities than those available in the city. Jenkins (2013: 52) offers a perspective here, as he illuminates fandom as a perspective from which to approach particular texts. He considers exactly what is needed to transform a book or a film into a cultural object, something related to the viewer's perspective. Focusing on texts, Jenkins says that fannish readers inevitably go beyond the meanings attributed to the text by its original author. ${ }^{2}$ In his opinion, there are three features that define the way that fans approach texts: information is made meaningful through immersion in social practices; re-reading plays a pivotal role within fan culture; and fan-created texts reflect key aspects of fans' lives and experiences. In this context, we want to determine what role the Internet plays in the formation of communities in which texts are transmitted and interpreted. Young people's use of the Internet allows for this general framework to be made specific, opening up new challenges and opportunities (Jenkins, Ito and Boyd 2015). Adolescents inevitably explore new discourses, linked to certain practices: words, images, and sounds are shared through platforms, and allow them to build and rebuild media content (Jewitt 2013). Such mediating tools must be understood as instruments related to innovative hardware and software that facilitate building stories. In light of current theoretical models (Davidson 2010; Ryan and Thon 2014) that examine personalized and connective media use and its consequences, the cross media concept is relevant from this perspective. Clear contrasts and complementarity can be determined in the use of networks in this context, such as Instagram, Twitter, Vine and WhatsApp, all of which are used by fan communities in related ways. Baym (2015) recently noted that online groups often develop a strong sense of group membership by sharing their productions. She identified five qualities in online groups: the sense of space, shared practice, shared resources and support, shared identities, and interpersonal relationships. A crucial idea there is that people, when they relate online, build specific spaces from which texts can be reconstructed and reinterpreted. 


\section{Online and offline friendships: the dilemma of public and private spaces}

Mobile phone use is currently associated with social networks and communities, but it is also linked with new processes in human relationships. Mobile digital media have generated a convergent world that creates new spaces and forms, as well as a new kind of audience (Nightingale 2011). Three main issues are particularly relevant in this respect and we will explore them here. First, teenagers who participate in the fan community pursue friendly personal relations. Ito (2013) reflects on friendship mediated by digital instruments. She shows that teenagers consider social networks as a way to be in contact with their peers, and explains that these activities contribute to negotiating identity, gossip, collaboration and information exchange, or just to having fun. Also, through the Internet, young people become part of global communities that allow for new kinds of relationship. By their implicit or explicit commitment, they acquire a sense of respect for other people, and an awareness that their relationships are governed by specific rules. Second, young people need to navigate between online and offline friends in specific ways. Because there are many dimensions that define physical presence which are absent online (Boyd 2014; Turkle 1995) people must consciously create digital identities when they are present on social networks. Furthermore, not all online environments are identical. Third, forms of relationship between our personal (private) and collective (public) lives constitute a relevant factor in processes of fan participation. In this context, classical authors help to confront social processes that are hard to understand today. According to Bakhtin, Holquist and Emerson (1986), people become individuated (as "persons") when they each overcome the private sphere by entering into conversations with others. The person is constructed as such by his/her presence in a public sphere, contextually related to society, history or culture. Now, people build their public and private profiles on social media. Holland et al. (1998) and her colleagues help to amplify this approach. According to them, people mediate between their private and public lives by building imaginary worlds. Cultural worlds, they say, are populated by familiar social types, and even identifiable persons. Identities grow through continued participation in positions defined by the social organisation of those worlds. Boyd (2014) also refers to the relationship between private and public life among adolescent girls. She makes a very useful distinction between "being in public" and "being public". According to her, "being public" (but at the same time having a private life) is a process, because social situations are not static.

\section{Participants and their practices: an empirical approach}

Our research is part of a larger project on which we are currently working. It examines teen activities in a participatory culture framework. We focus on young people aged between eight and fourteen years old using digital mediators. In this article, we look at five girls participating in the One Direction fan community, combining the use of several social networks including Twitter, Instagram, Vine and Wattpad. All of them go to the same school in Madrid, Spain, which is where 
the research team did its work. The selection of these five girls was based on the facts that they were active media users, producing new content in online fan communities instead of retweeting or simply marking other people's publications as favourites; indeed, re-posting was one their main activities. We knew of their friendship by informal conversations with the girls. Moreover, they attended the workshops organized by the research team outside of the school environment. In addition, the girls had a clear conception of their shared interests as fans; boys in their class, for instant, were different because they participated more interested in video games communities. The preferences expressed by our sample of girls reflected gender differences when boys and girls interact with technology. Other research has alluded to this fact (for example, Kafai et al. 2008; Roddy 2013; Keller 2012), although it does not fall within the scope of our paper.

The five girls that we selected were followed during the school year and we considered how they bonded as members of one connected community, and not only through specific objects (Rogoff et al. 1995). Although the girls were One Direction fans, they were also followers of other music celebrities. While Luisa, Ana and Elena followed One Direction only, Dani was mostly a fan of a Spanish singer called Melendi. Lucía, who was also a "One Directioner", also liked Magcon. Belonging to two communities allowed Dani and Lucía to compare what happened in each of them and to become aware of the peculiarities of each. From a methodological point of view, our study approached online and offline participation, aiming to understand adolescent activity as a situated practice involving processes which construct shared meaning. For the data collection, we also combined offline and online activities. First, we considered the girls' offline lives, interacting with them during the workshops at the community centres and at school. We also held personal and focus group interviews, totalling four hours and twenty minutes. Finally, their participation in online social networks was examined. We adopted an ethnographical perspective, mixing narrative and analytical interpretations, and seeking to overcome the contrasts between them (Lacasa, Martínez-Borda and Méndez 2013). Approaches from digital ethnography suggest focusing on specific concepts in order to present and discuss the data (Pink et al., 2015). Rogers (2013) proposes three principles: to use the analytical tools provided by the network; to consider online elements such as links, tags and other digital objects; to take into account that these elements can be combined in specific cultural and social contexts (posted, reposted, etc.). These ideas will direct our approach to data collection and analysis. NVivo 11.1.1 software for Mac supported the transcription process and was used for our qualitative analysis. When using the program, the downloading of Twitter accounts through Caption allowed for an in-depth analysis of the transcription in order to define specific dimensions (nodes, using the program terms or categories in more classical approaches) and look for examples. To explore fan creations on Instagram and Vine, we used web access through Iconsquare and Vine.com. 


\section{Main activities on the Internet}

An analysis created by NVivo 11.1 allowed us to have specific information about the girls' online presence. TABLE 1 includes the girls' activities in social networking platforms, as they appeared in our own social network. Ana was the only girl who has a Twitter account dedicated solely to participating in the fan community. The identity of this account was anonymous; she had another one that family and friends knew.

TABLE 1. The girls' participation on the Internet

\begin{tabular}{|l|l|l|l|l|l|l|}
\cline { 2 - 7 } \multicolumn{1}{c|}{} & LUISA & LUCÍA & $\begin{array}{l}\text { ANA } \\
\text { PERSONAL }\end{array}$ & ANA FAN & ELENA & DANI \\
\hline TwITTER & & & & & & \\
\hline Tweets & 196 & 919 & 208 & 1385 & 133 & \\
\hline Re-tweets & 112 & 850 & 115 & 648 & 122 & \\
\hline Likes & 2446 & 1161 & 262 & 959 & 367 & \\
\hline Followers & 146 & 98 & 89 & 92 & 58 & \\
\hline Following & 173 & 130 & 144 & 208 & 65 & \\
\hline INSTAGRAM & & & & & & \\
\hline Posts & 159 & 19 & 19 & & 18 & 49 \\
\hline Followers & 584 & 428 & 347 & & 508 & 648 \\
\hline Following & 525 & 319 & 667 & & 500 & 614 \\
\hline VINE & & & & & & \\
\hline Posts & & 32 & 8 & & 7 & \\
\hline Followers & & 32 & 59 & & 24 & \\
\hline Following & & 53 & 38 & & 31 & \\
\hline Likes & & 254 & 661 & & 26 & \\
\hline WATTPAD & & & & & & \\
\hline Followers & 45 & 49 & 39 & & 31 & 17 \\
\hline Following & 55 & 48 & 43 & & 28 & 20 \\
\hline Author & & 16 & & & & \\
\hline $\begin{array}{l}\text { Stories } \\
\text { On the list }\end{array}$ & 11 & 203 & & & & \\
\hline Views & & & & & & \\
\hline Likes & & 22 & & & & \\
\hline Comments & & & & & & \\
\hline
\end{tabular}

An initial quantitative analysis by NVivo of the girls' activities on Twitter showed the precise number of tweets, retweets and likes for each account with respect to the total of that account. They express different levels of fan activity. The number of tweets revealed each fans' own productivity. According to our data, even though the girls sent direct and public message to members of the band, they 
never received any answers from them. Nevertheless, Ana was the girl who tweeted the most through her fan account (46\%), twice what she retweeted $(22 \%)$. Lucía was also more active than her peers when it came to producing tweets $(32 \%)$. Her account showed tweeting and retweeting in roughly equal proportion. The clearest finding in relation to the other two girls was that their most frequent activity on Twitter consisted of "favouriting" others" existing messages (for Luisa, $83 \%$ and for Helena 58\% of output). Such data help us understand how practices differ when considering particular clusters of activity across different social networks (Boyd 2014). They clarify what it means to be an active participant and in some ways a producer, not just a receiver of information (Jenkins, Ito and Boyd 2015).

The word clouds included in FIGURE 1 provide information regarding the girls' Twitter interactions. The frequency of retweets and likes is excluded, because we are seeking to gain a clear picture of fan initiated activity. Using NVivo, an initial quantitative analysis of the fans' productivity on Twitter shows the occurrence of fifty words that appear most frequently in their accounts. Once more, several differences appear between different members of the sample:

FIGURE 1. Word frequencies in the Twitter accounts

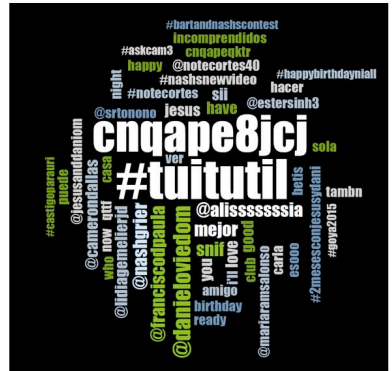

LUISA

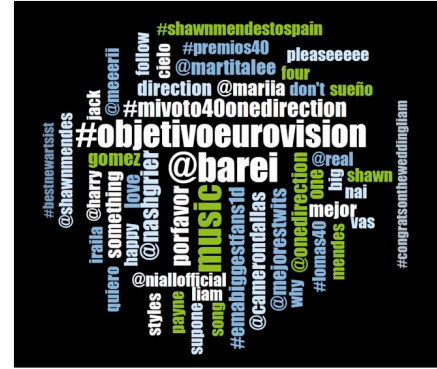

LUCIA

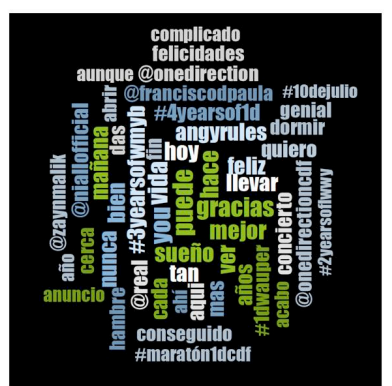

ELENA

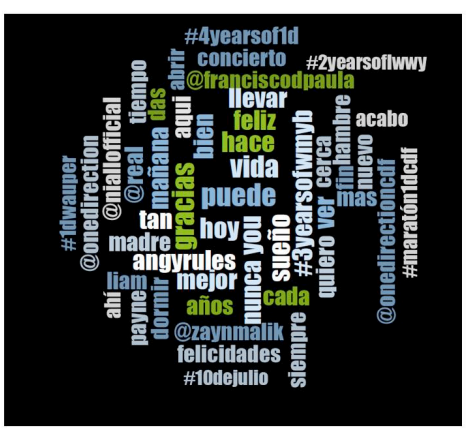

ANA Personal (also Fandom)

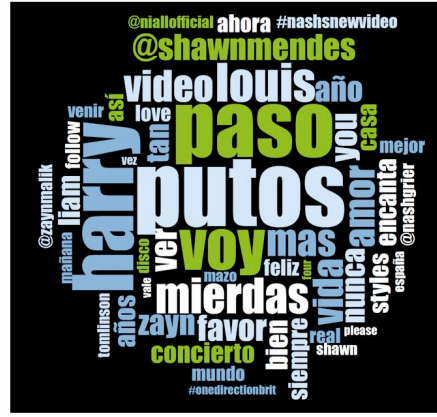

ANA Fandom

Some of the most significant differences are evident between Ana's fan and personal accounts, which contrast with the most active One Direction fan, Lucía. In her fandom account, Ana's allusions to particular people - whether musicians or other participants - are less frequent than among the rest of the girls, 
representing less than $5 \%$ of the tweets. Similarly, hashtags appear in only $2 \%$ of her posts. This data could be a sign that she considers the fan account as a place for self-expression (Nightingale 2011), often referring to specific events in her daily life, for example. In one Twitter entry there she said: "Now I need to go get my final grades, I am shit-scared". In addition, she uses many "colourful" words here which she would probably not use if the account were not anonymous. The most frequently used words included putos ("fucking"; 6\%), mierdas ("crap"; 3\%) and paso ("I don't care"; 5\%). Words which dominated other accounts - "Harry" (5\%), amor ("love"; 3\%) and vida ("life"; 3\%) - were also frequent. Lucía's word cloud, meanwhile, was very different. Allusions to other fans or members of One Direction and Magcon represented $27 \%$ of her 50 most used words. Also very common was the use of hashtags $(21 \%)$. The other two girls showed a similar pattern, although their use of these two strategies was somewhat less frequent than in Lucía's account. References to contact with other people or musicians is more frequent in Luisa's account (23\%) than in Elena's (9\%). Moreover, both Luisa $(21 \%)$ and Elena (18\%) frequently use hashtags; even if their posts do not always get a response, their use of hashtags could be interpreted as indications that these girls are actively looking for support from other members of the fan community.

\section{Listening to the girls' voices}

In a second analysis of the data, both interviews with the girls and data from their Twitter accounts were inductively analysed using Nvivo software to discover a set of key themes outlined in the appendix. By focusing on our three categories of investigation - building heroes, networked lives, and negotiating the private/public - a series of nodal themes emerged that guided the selection of the interview transcript fragments included in the following results. Although the analysis was conducted by using written text and images, the possibility offered by NUDIST (Non-numerical Unstructured Data Indexing, Searching and Theorizing) approaches to listen to the girls' voices during the interviews at any point during the analysis proved very helpful.

\section{a) Teens and music celebrities: building heroes}

Like many other people, adolescents can build imaginary worlds. ${ }^{3}$ These worlds are dynamic. They stem from specific perspectives related to participants' roles and cultural situations. We invited the teens to explain why they followed certain celebrities, defined in our research as heroes. The following interview transcript fragment is divided into two parts, both of which relate to how the girls defined who might qualify as a hero or, as they say here, "idol".

FRAGMENT 1. Seeking a definition of people to follow

ANA: For me, an idol is someone to follow.

LUISA: Or someone who is not real, like Frozen or Elsa.

ANA: What? Elsa? Is she an example to follow?

LUISA: Elsa! 
RESEARCHER: Listen, did you know some singers are virtual characters? This singer is virtual; he does not exist.

ANA: But I don't like him (as an idol)... because he isn't a real person and he has no personality. I don't understand how you can have an idol who has no personality. Because he is untruthful and you can't admire him. You can appreciate how he sings, or you can like how he dresses. But for me, an idol is not only someone you like for how he sings or dresses, it's also about personality, about what he is like, what he does for fun.

Clearly, the girls do not agree. For one, an idol is someone real; for the other, the idol is situated in the fictional world of Disney. As we dug deeper into their idea of an idol, we found once more that personal and collective worlds intermingled. In the following example, we see how Ana prefers to rely only on real, non-virtual idols, ones anchored in the qualities that she admires in everyday life.

The ideas expressed by Bakhtin, Holquist and Emerson (1986) are particularly relevant in this context as they explore the relationship between an author and his/her hero. For Bakhtin, the hero is the core of the creative process; the author approaches him or her as a human being by assembling all the cognitive-ethical determinations that make him or her a unique figure, a whole, a unit of meaning. Bakhtin considers the creation of the hero as an aesthetic process based on the dialogue that people build from the notion of totality and exteriority. Ana and Luisa approach their heroes by focusing on the features they admire (Duffett 2013). The heroes then become a starting point for adolescents' creative participation in virtual and social networks (Jenkins, Ito and Boyd 2015).

The hero, termed an "idol" by the girls here, is someone who ultimately becomes an object in whom relations of affection and closeness are invested (Michailowsky 2014). For example, when the researcher asked Luisa why she used a fan account, why she followed celebrities, her answer showed that she wanted to feel close to someone: "Because in a way you are closer to celebrities than in real life. Because you talk to them. Well, listen to them... [laughs]". When Ana, however, admitted that they did not respond, Luisa reaffirmed the idea: "That's right, they do not respond, but you hear them speaking, which is something". Fans admire people they want to interact with, people to whom they want to listen.

It is clear that girls seek a close relationship with the celebrity, whom they have turned into a hero in some way, and onto which they project their affection (Barron 2014). Lucía's opinions supported this interpretation. At one point in the interview, the investigator asked her whether she believed her relationship with the band was similar to the relationship between soccer fans and the team they supported. She said that she thought they were very different. In her explanation, she highlighted her attachment and emotional connection with the hero, something she does not attribute to a relationship with a sports team. When we asked her to go into more detail, Lucía said:

We (the fans) are crazy, but the thing is that, all over the world, all fans are crazy!" Asked to be more specific, she replied: "I wouldn't give my life for 
them, but it is true that we have a special affection for them, because we know everything they do. Because they are on social networks so much!

To understand this emotional attachment with a hero (Duffett 2013) - someone who can may become a role model (Michailowsky 2014) - we need to analyse how the process of the shared representation on social networks constructs the roles of valued celebrities. The data there shows different types of information. On one hand, there is what might be considered objective information, transmitted by official accounts; on the other, there are the micro-and macro-stories by which the girls represent the everyday life of their heroes. Here are some examples:

FRAGMENT 2. Twitter as the source of true information

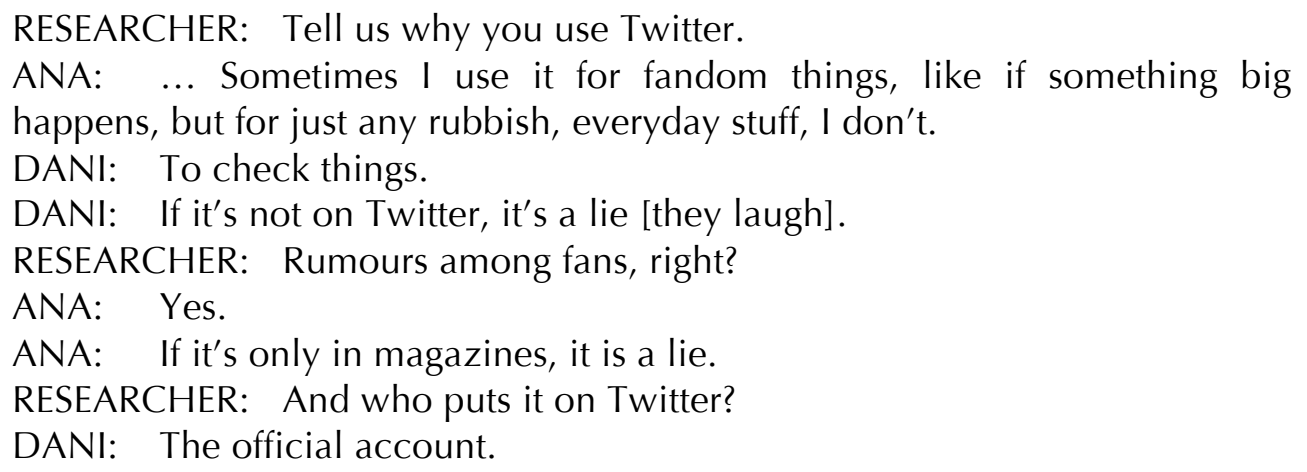

The above dialogue shows at least two important ideas. First, there is a certain contradiction in the girls' thinking. They consider the information posted online by celebrities' publicists to be true; Dani states this when she refers to official accounts. At an earlier point in the interview, however, they are much more critical, censoring the role of the publicists. Boyd (2014) has pointed out that this is related to the complexity of the information transmitted by social media. Second, it is clear that adolescents are highly capable of assessing the validity of information that appears in different social networks and considering its specific nature. For example, when they compared the Internet with magazines, Dani told us clearly: "By the time you go to look for things in magazines... someone has already retweeted it". Ana, however, said that she liked magazines because they offered more than just information: "I check which poster comes with each one, and I buy whichever one has a nice poster". This example offers a very interesting example of the material culture that surrounds fandom. Adolescents, of course, have put posters of their heroes on their bedroom walls and wardrobes for generations (Salinger 1995). Baker (2012: 519) shows how fannish use of material culture can reflect the values of online groups: "The process of giving and receiving material culture can strengthen bonds between individuals by using the new technologies of the internet".

Lucía's interview helps us to look more closely at how adolescents become producers of new information when they build short or long stories (DeCordova 1990). Work on fan fiction (Black 2008; Hellekson and Busse 2014) widely recognizes this type of productivity. When Lucía explained the content of her account, she told us about the types of information available on the Internet, 
referring to some of the different genres of online content: "Look, for example, these are fans ..., this is a fandom video, these are famous Vines, these are Spanish fans, and they are making a video about their daily lives". Allusions to the lives of heroes as they appear on Vine becomes a source of inspiration for the girls to build long or short stories. When such fans participate in these communities and use associated apps, they inevitably employ multimodal discourses (Jewitt 2013) as tools for building shared representations of the celebrity (Davidson 2010). What is important is that there is affection in the girls' stories. At one point in Ana's interview, we asked about the content of messages circulating through different networks of the fan universe. The girls discussed what they considered representative in fan accounts by considering the Twitter posts shown below (FIGURE 2):

FIGURE 2. Twitter posts

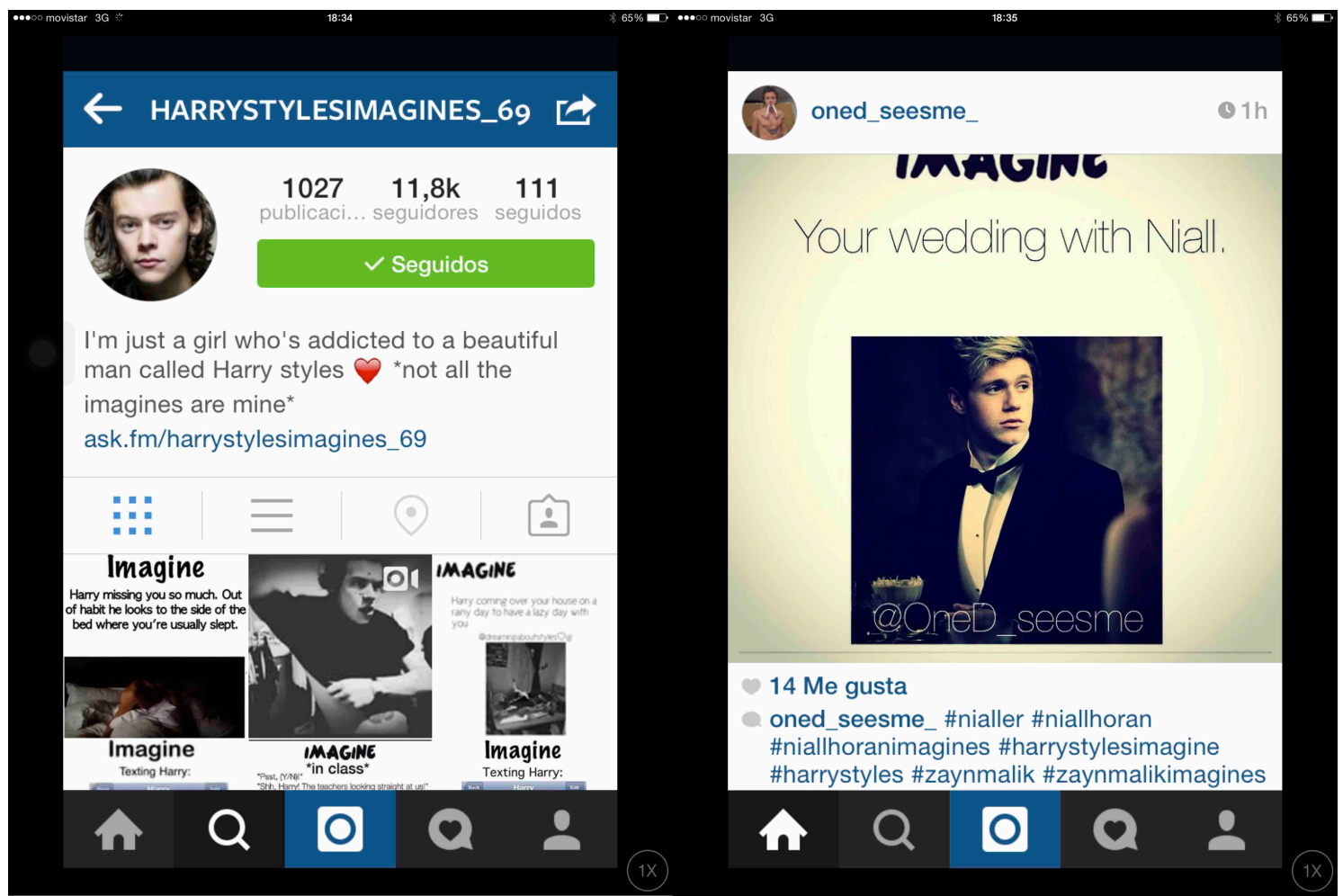

FRAGMENT 3. Imagination as a driver for the creation of short stories

ANA: You see? It says, Harry, I miss you. Let's see a moment. Look at the side of the bed where you usually sleep. And he appears in bed.

RESEARCHER: Do you mean they write about feelings and things like that? ANA: Yes, for example, imagine you're with Harry, and you leave. And he forgot the goodbye kiss. And he appears there opening the door.

ANA: Look at this other picture where he wears a shirt and a suit, and they write: "Marrying him". 
Twitter provides fans with plentiful opportunities to reconstruct their hero's life in the form of a series of micro stories, but other online platforms can condition and facilitate different forms of fannish productivity. Wattpad is a social network which encourages its participants - often adolescents - to write about their heroes (or other subjects) in a much longer form, since its supports uploaded novels. Lucía is the author of a book with seventeen chapters, which other readers can comment upon. She designed the cover herself and, when describing the book, told us she was projecting her own world: "It's my world, you know?"

\section{b) Teens, One Direction communities and networked lives}

We have defined a community as a set of people who share values, goals and ways of acting and who are aware of belonging to a group. In addition to this, they built a common framework for the construction of meaning. Implicitly or explicitly, they must communicate and share interpretations and meanings designed to organize their practices when interacting with other people, material and immaterial objects. In this article we focus on how female adolescents act and make meaning when participating in fan communities of their peers. More specifically, we will demonstrate the ways that these features are present in girls' practices as they follow One Direction. To do that, we first explore how the girls begin to be conscious of their participation as fans; second, we examine their motivations for being part of the fan community. Finally, we consider how they use multimodal discourses as tools which enhance and extend their participation. So how the girls become aware of their identity as group members? Their group allegiances are exposed by discussing conflicts of interpretation around the heroes that they follow. Other authors also refer to possible problems in fan communities (Bennett 2014; Jenkins 2014). Chin (2010) notes that conflicts can exist in communities, even when there are shared interests. These conflicts can sometimes become a unifying element. From that point of view, Baym (2015: 81) shows how many online groups develop a strong sense of identity. This, for example, was what Lucía, a Magcon fan, explained during the interview when she referred to her favourite band:

FRAGMENT 4. Being a community member

LUCÍA: They were discovered in Vine. A producer saw them and got them together, they already had plenty of followers. So their fans could see them. They started doing fan conventions with those guys all around the United States and they were called Magcon... But the problem was that they split up around one year ago and some people tried to form a new Magcon. I don't like it at all. I'm all for the original Magcon.

RESEARCHER: And then, did you stop following them?

LUCÍA: I don't [follow them], they are impostors. For me they are impostors, because it just not possible: Magcon ended and they got others who are supposed to be Magcon too, but it is not the same.

Lucía was attached to the individuals that she followed. Therefore, she could not allow them to be replaced or superseded by others. Difficulties and problems 
contributed to make her aware that she loved the original band, not simply their brand.

Next, we we must ask what it means for teenagers to become part of a particular fan community. As Miller and Goodnow (1995) explained several years ago, interests and motivations may go beyond immediate action. Adolescents' goals may also differ significantly. In our interview with Ana and Luisa, the researcher asked for reasons that, according to them, lead people to join the fan universe.

\section{FRAGMENT 5. COMMUNITY AND SHARING INTEREST}

RESEARCHER: Why do you think people look for this kind of world where they are connected with other people?

LUISA: I think it's for fun. It's not that you're bored ... You don't think, "My life is rubbish, I'Il go on Twitter"... It's not like that, it's just that you say... "I don't know, I'll go on Twitter" [they laugh].

ANA: You know, there are people who have the same opinion as you. That in the real world it is more difficult. For example, you go into an account and you know who they are. But, for example, for a real person to tell you all these things, that is more complicated, because they may need to have more confidence to tell you. But if you have it on your profile then you say. OK, this person shares my views.

Many of the ideas in this paragraph appeared frequently elsewhere in the interviews. According to our interviewees, belonging to the fan community is something that allows individuals to have fun and, of course, to find others with similar interests; something which would be much more difficult in the offline world. Connections happen more easily because relationships are mediated by a specific tool, the Internet; fans describe themselves in their profiles, so this makes things easy. People do not need to ask, because like-minded others have already introduced themselves beforehand.

Lucía, by contrast, was not just focusing on having fun. She came across as an enthusiastic activist (Jenkins, Ito and Boyd 2015), an intense follower of the Magcon community. She had a strong sense of belonging, and was committed to undertaking collective action. When we spoke, she wanted to achieve a very specific goal: getting the group to visit her country. Bennett's (2012) work can help to understand how such fans mobilize through their social networks. The following paragraph describes Lucía's activity based on her personal and collective goals.

FRAGMENT 6. Community and commitment in action

LUCÍA: And then we have a lot of accounts on Twitter, Instagram, Tumblr, Pinterest and all these social networks. And we are creating a kind of revolution to get Magcon to come back because we want them to come back and visit our countries so we can meet our idols... But the problem is that they are not listening to us, and there are more and more of us, but it is difficult. 
RESEARCHER: Why do you think they aren't listening to you?

LUCÍA: No, it's not that they aren't listening, it's just that we are one among a million. What can we do?

RESEARCHER: But how can you be just one among a million, if you're organizing groups? Are these groups close to here?

LUCÍA: There may be people in Peru and Chile, mainly Latino girls. There are also Americans that want Magcon to come back, but we don't follow each other, we don't have the same ideologies; some don't want Magcon to come back, others are against a particular person in Magcon...

Lucía immediately recognizes that as a country Spain does not play a major role, and, as we can see in the dialogue, there are tensions within the fan community. She attributes these conflicts to differences in ideology, but the problem is more specific. She admits that the band members are not listening to their fans. Even though they can check online and see the messages, they have abandoned their following. In this situation, Lucía responds with her desires rather than the reality: "I want to see them, I want to meet them, or at least see them from three kilometres away. To see them would be crazy, just like what happened with One Direction; to see them was good, good, good!" Interpreting Lucía's comments, we can see she has a clear goal. Jenkins, Ito and Boyd (2015) consider such fan practice as related to the idea of civic compromise. Young people are looking for specific strategies to act in the global community in order to change social life (Bennet 2012).

We have already mentioned that adolescents use networks in diverse ways. This must be interpreted in relation to an awareness of the discourses used and the functions and roles of each particular network (Jewitt 2013). Moreover, using these tools, the girls participate in a universe of shared meanings that allow them to interpret specific texts (Jenkins 2013). During the conversation, Lucía is asked about this topic:

FRAGMENT 1. Specificity of accounts and discourses

RESEARCHER: And why do you think fans use so many social networks?

LUCÍA: Well, Instagram for example is for photos, photos of what they do. Twitter is more immediate, Twitter is all about the moment, about what you are doing in a particular moment, because ... they may have some news and share them on Twitter.

RESEARCHER: So Twitter connects everything?

LUCÍA: Yes, then we have Snapchat, which is what they are doing each second, Vine with the cartoons they create and where they speak.

Lucía is also a Vine user, and she believes that all celebrities have accounts on most social networks. She prefers Vine and YouTube because she likes only to watch videos, and she mentions that she does not upload any. Therefore, we can see that networks are associated with the applications that make them possible, and that each uses specific discourses (Jewitt 2013). This data could be interpreted according to the previous research: first, those referring to the multiple tools used to participate in the community in order to achieve specific goals (Cole 1995); 
second, considering more recent studies related to digital participation in social networks (Boyd 2014; Jenkins 2014).

\section{c) Living online and offline in fan communities}

Participating on digital social networks means opening up new paths to peer relationships. We will go in deep on that topic when adolescents participate in the fan community. Three main topics will be examined: how the girls share fannish interests online, how they mediate between private interactions and public lives, how the girls use the Internet to look for physical relationships. It is clear that friendly interpersonal relationships are established by moving from Twitter to WhatsApp, and then to life offline. The following transcript shows an example:

FRAGMENT 8. Adolescents friendships within the fan community

RESEARCHER: But you found these virtual friends because both of you were fans?

LUISA: Yes, of course, because we have something in common.

ANA: But then we don't just talk about One Direction; at the end of the day you are talking about your opinions about other things. You start talking about that, but also about many other things.

The use of social networks evidently expands individual life worlds as people connect online (Goggin and Hjorth 2014). Users' exchanges function by mediating, complementing, and increasing their face-to-face interaction (Boyd 2014). Social networks are used, therefore, to find friends and form increasingly close relationships. As adolescent girls interact through WhatsApp, or use private messages on Twitter or Instagram, they have conversations about many more topics that just being a fan. When thinking about their communications practices, not only must physical interaction be explored, but also the content of conversations; some of it guides our attention beyond what it means to be a fan. The girls also recognized that their online friends have offline lives, that in some sense "they are real". According to Lucía:

The thing is that I have friends I met through Magcon. If there were no Magcon, I would have never met some of my friends. I've seen them in pictures. There is no way an imposter could create this whole life. I know they are real.

Lucía is aware that her online friends also have a physical reality offline. Sherry Turkle (2008) has suggested that as media use develops online, face-to-face talks are increasingly becoming seen as a specific form of human activity. Her work may be useful here, as Lucía's response suggests that a particular conception of the nature of reality is associated with her use of mobile technology.

The fan community creates a particular space protected by a certain anonymity. Teenagers in the community can express many of their concerns without any adult supervision, and away from the gossip which is sometimes present in peer relationships. The fan universe opens up opportunities for people 
to express concerns and aspirations in an environment where they feel supported by a community; a point that could be related to the idea of fans acquiring social capital (Chin 2010). That was what we discovered when Ana told us that she had a fan account known to nobody else, not even her closest friends: "I have 3 accounts - one personal account, one fan account and another one to vote". Ana is very aware of how she uses each account. The messages she posts on each of them are different. As we explained before, one of them, which she called "personal", was used to interact with her friends from school, and she is aware that her family knows about it. This is a description of the information that she posts there: "Who I am, I don't know. I mean, if I am meeting up with people, I might put that on there, and mention the people I am meeting up with and things like that". As Boyd (2014) points out, social media allow new dimensions of personal expression online. While Ana does not have any problem with identifying herself, or mentioning her real friends on her personal account, her fan account is different: "My name is not Ana, and in fact I never give my real name". In a subsequent interview, Ana returned to this topic. The researcher asked if, in her opinion, there was a difference between the words "personal" and "intimate". This was her answer: "Well, personal... is kind of me, because it's me and you see me. Intimate is like, I don't want anybody to see it". When we analysed the account which Ana said was secret, she offered some explanations about why she had hidden it. Her fan account was a world where she interacted with other fans in a more open way, without any limits to her expression. She built micro-stories (Hellekson and Busse 2014) - fan fiction about her heroes - and she was confident that she could express her most intimate world there and share it with others who had the same interests. Even though she expressed things there that she felt should be hidden from unwanted observers, she still felt protected.

A final important activity in the One Direction fan community is something that the girls define in Spanish as quedadas, or "meet-ups". Adolescents use the term to refer to fan meetings which usually occur offline, but are scheduled online. Two factors make these meet-ups important to our study: the fact that they facilitate offline contact between fans, and their processes of organization.

FRAGMENT 9. Meet-ups - What are they? How are they organized?

LUISA: And there are also meet-ups. Some of which are prestigious, so to speak, because they are like prize draws, like the one Ana and I went to, and others that are just regular "meet-ups".

RESEARCHER: Selected people?

LUISA: From the WhatsApp group, they say "let's meet this day, let's all go to this place", and we go to...

RESEARCHER: And where do you go?

LUISA: To the city centre, or around Madrid.

RESEARCHER: Have you ever been to any of these?

ANA: No, I haven't.

Two types of meet-ups can be discerned here. First, there are ones organized by leaders with interests in the fan community. Luisa considers these "prestigious". They may be, for example, announced on radio stations which target young 
audiences; such stations may stage lottery draws featuring invitations as prizes or gifts. They imply that people are there by previous invitation, so fans who attend feel privileged and motivated. Second, there are less formal meetings organized by the fans themselves through WhatsApp. These allow them to have face to face relations after experiencing first contact online. Facilitated, again, by their mobile phone numbers (when using WhatsApp), or by their private Twitter messages, it is evident that the teenagers fully exploit the possibilities offered by different social networks. Some years ago, Coleman (2011) showed that the online/offline distinction is not always relevant. Indeed, it may come more from the perspective of researchers than from the girls. What is clear is that they need offline physical contact with the fan community.

\section{Conclusion}

Our analysis of adolescent activity in fan communities suggests that researchers face new challenges when it comes to examining the use of digital media. In general terms, the results indicate that the Internet has introduced mechanisms that were not present a generation ago. More specifically, teen participation in fan communities is now clearly influenced by fans' presence on online social networks. In accordance with our theoretical framework, each section presented in our results leads us to suggest new avenues for future research.

According to Michailowsky (2014), people need heroes to give them a reason to live. We looked at the ways in which adolescents in the fan community transformed the status of the object they loved from celebrity to hero, someone in whom they developed affective attachments of admiration and love. What we found was that girls used the Internet is a meaningful space where they looked for personal contact with their favourite celebrity. Even if that contact never occurred, what it showed was that adolescents preferred "real" people to, say, virtual reality or holographic constructs. Not only, as other researchers have noted (Baker 2012; Jenkins 2014), was the Internet a source of information and social capital; in our study, the girls were aware that the information appearing on it could be controlled by industries and publicists. In such situations, other fans shared criteria for establishing the quality of this information.

Digital environments have directed teenagers' skills when it comes to managing both social media interactions and participation in fan communities. Our second aim was therefore to examine the role that social networks played in the girls' lives. Like other researchers (Jenkins, Ito and Boyd 2015; Baym 2015), we discovered that the practices of the girls in fan communities have been transformed by their adoption of online social networks. What we found was that teenage users were able to make best use of each specific social networking platform because they understood its unique potentials to both transmit particular messages and find new audiences. Fans developed particular strategies for making contact with people of similar interests; some thought that looking at user profiles, for instance, would not have been possible offline. The Internet also made possible the use of new types of texts to extend social contact. Relations between tweets, retweets and likes show specific practices associated with the network. 
Such online activity created a framework for multimodal interpretation. In Lucía's case, participation on social media became a way to unite with other fans in pursuit of a particular, goal orientated activity (see Bennett 2012): she campaigned to get her heroes to come to her country. Her efforts demonstrate that Internet use can facilitate the pursuit of activism-specific behaviour patterns among adolescent girls.

Our third area of interest was to see how fans' online activity related to their offline world. What we found was that the personal relationships conducted online were not enough for the girls; they also want to share their common interests with other fans in the real world. Therefore, they organized what they called "meet-ups", which took place in real locations and offered experience of specific real times and spaces. Ana's practices were a good example of how the community provided a context for emotional expression, one might even say a "private" space, where girls could share their daily concerns. The differences between Ana's personal and fan accounts are relevant to this point. What our word clouds showed was that the ways she expressed her thoughts and ideas, and the discourses that she used, were very different on each account. Such results open new questions about the role of the fan communities as protective spaces where adolescents can build their identities (Holland et al. 1998; Turkle 1995, 2008).

As researchers looking at adolescents in music fan communities, our results lead us to further questions: What mechanisms are behind the construction of fan communities among adolescents when the celebrity is a simulated reality or a hologram? What is the role of shared online texts which mix together virtual and tangible objects? What interpretative processes allow both types of object to be complementary? In what ways have teens made best use of the dual aspects of anonymity and affective support in fan communities? New research will be needed to answer these and other questions that might explain more about adolescent girls' participation in fan communities.

\section{Endnotes}

${ }^{1}$ We need to point out that we use the term "hero" to define figures who are the object of fan attachments. Our use of the term does not involve any other particular connotations, and the fact that is present in these pages rooted in the old comic and new comic studies, referring to superheroes. Henry Jenkins (2015), in a recent audiovisual production, related superheroes to human imagined realities: before we can change the world, he says, we need to imagine a new one. The term "idol" was only used when mentioned by the girls or the researcher.

2 "Fannish" is a term from fan studies meaning "pertaining to fandom" (Duffett 2013: 293).

${ }^{3}$ The work of Dorothy Holland et al. (1998) is particularly useful for thinking about this phenomenon of world building. 


\section{Acknowledgements}

We are grateful to the Spanish Ministry of Education, the University of Alcalá and the Digital Ethnography Research Centre (RMIT, Melbourne) for their support in writing this paper. We thank the girls and their parents for permitting their participation; their names have been changed for the sake of anonymity. Finally, we are thankful for the permission we received to reproduce illustrations from fan Twitter accounts.

\section{References}

\section{Bibliography}

Baker, A. 2012. The Exchange of Material Culture Among Rock Fans in Online Communities. Information, Communication \& Society 15 (4): 519-536.

Bakhtin, M. M. \& Holquist, M. 1981. The Dialogic Imagination: Four Essays. Austin, TX: University of Texas Press.

Bakhtin, M. M., Holquist, M. and Emerson, C. 1986. Speech Genres and Other Late Essays. Austin, TX: University of Texas Press.

Barron, L. 2014. Celebrity Cultures: An Introduction. Thousand Oaks, CA: Sage Publications.

Baudrillard, J. 2005. The System of Objects. London: Verso.

Baym, N. K. 2015. Personal Connections in the Digital Age. Malden, MA: Polity Press.

Bennett, L. -

2012. Fan Activism for Social Mobilization: A Critical Review of the Literature. Transformative Works and Cultures 10.

http://journal.transformativeworks.org/index.php/twc/article/view/346/277; Accessed: 15 April 2016.

2014. Tracing Textual Poachers: Reflections on the Development of Fan Studies and Digital Fandom. Journal of Fandom Studies 2 (1): 5-20. http://dx.doi.org/10.1386/jfs.2.1.5_1,2,5-20

Black, R. W. 2008. Adolescents and Online Fan Fiction. New York: Peter Lang. Boyd, D. 2014. It's Complicated: The Social Lives of Networked Teens. New Haven, CT: Yale University Press.

Chin, B. 2010. From Textual Poachers to Textual Gifters: Exploring Fan Community and Celebrity in the Field of Fan Cultural Production. PhD thesis. Cardiff: Cardiff University.

Cole, M. 1995. The Supra-individual Envelope of Development Activity and Practice, Situation and Context. New Directions for Child and Adolescent Development 67: 105-118.

Coleman, B. 2011. Hello Avatar: Rise of the Networked Generation. Cambridge, MA: MIT Press.

Davidson, D. 2010. Cross-media Communications: An Introduction to the Art of Creating Integrated Media Experiences. Pittsburgh, PA: ETC Press. 
DeCordova, R. 1990. Picture Personalities: The Emergence of the Star System in America. Urbana, IL: University of Illinois Press.

Duffett, M. -

2013. Understanding Fandom: An Introduction to the Study of Media Fan Culture. New York: Bloomsbury.

2014. Fans Words. In M. Duffett Ed. Popular Music Fandom: Identities, Roles and Practices. New York: Routledge: 146-164.

Goffman, E. 1956. The Presentation of Self in Everyday Life. Edinburgh: University of Edinburgh, Social Sciences Research Centre.

Goggin, G. and Hjorth, L. 2014. The Routledge Companion to Mobile Media. London and New York: Routledge.

Hellekson, K. and Busse, K. 2014. The Fan Fiction Studies Reader. lowa City, IA: University of lowa Press.

Holland, D., Lachicotte, W., Skinner, D. and Cain, C. 1998. Identity and Agency in Cultural Worlds. Cambridge, MA: Harvard University Press.

Ito, M. Ed. 2013. Hanging Out, Messing Around, and Geeking Out: Kids Living and Learning with New Media. Cambridge, MA: MIT Press.

Jenkins, H. -

2013. Textual Poachers: Television Fans and Participatory Culture. London and New York, Routledge.

2014. Fandom Studies as I See It. The Journal of Fandom Studies 2 (2): 89-109.

2015. Important Reminder: Superman Was an Undocumented Immigrant.

Fusion, 16 March, http://fusion.net/video/103908/superheroes-are-

undocumented-immigrants-and-the-other-way-around/; Accessed: 25 September 2016.

Jenkins, H., Ito, M. and Boyd, D. 2015. Participatory Culture in a Networked Era: A Conversation on Youth, Learning, Commerce, and Politics. Cambridge, MA: Polity Press.

Jewitt, C. Ed. 2013. The Routledge Handbook of Multimodal Analysis. London and New York: Routledge. Second edition.

Kafai, Y. B., Heeter, C., Denner, J. and Sun, J. Y. 2008. Beyond Barbie and Mortal Kombat: New Perspectives on Gender and Gaming. Cambridge, MA: MIT Press.

Keller, J. M. 2012. Virtual Feminisms. Information, Communication \& Society 15 (3): 429-447.

Lacasa, P., Martínez-Borda, R. and Méndez, L. 2013. Media as Practice: Narrative and Conceptual Approach for Qualitative Data Analysis. Studies in Media and Communication 1 (2): 119-131.

http://redfame.com/journal/index.php/smc/article/view/231; Accessed: 25 September 2016.

Lave, J. and Wenger, E. 1991. Situated Learning: Legitimate Peripheral Participation. Cambridge: Cambridge University Press.

Lévy, P. 1997. Collective Intelligence: Mankind's Emerging World in Cyberspace. New York: Plenum Trade.

Ling, R. 2007. Children, Youth, and Mobile Communication. Journal of Children and Media 1 (1): 60-67. http://dx.doi.org/10.1080/17482790601005173 
Marwick, A. and Boyd, D. 2011. To See and Be Seen: Celebrity Practice on Twitter. Convergence: The International Journal of Research into New Media Technologies 17 (2): 139-158.

Michailowsky, A. 2014. Researching Your Favourite Artist: Methodological Observations of a Brazilian Popular Music Scholar. In M. Duffett Ed. Popular Music Fandom: Identities, Roles and Practices. London and New York: Routledge: 71-85.

Miller, P. J. and Goodnow, J. J. 1995. Cultural Practices: Toward an Integration of Culture and Development. In J. J. Goodnow, P. J. Miller and F. Kessel Eds. Cultural Practices as Contexts for Development. San Francisco, CA: Jossey-Bass: 5-16.

Nightingale, V. 2011. Introduction. In V. Nightingale Ed. The Handbook of Media Audiences. Malden, MA: Wiley-Blackwell: 1-16.

Pink, S., Horst, H., Hjorth, J. P. L., Lewis, T. and Tacchi, J. 2015. Digital Ethnography: Principles and Practice. Thousand Oaks, CA: Sage.

Roddy, K. 2013. Toward a Feminist Superhero: An Interview with Will Brooker, Sarah Zaidan, and Suze Shore. Transformative Works and Cultures 13. http://dx.doi.org/ 10.3983/twc.2013.0476

Rogers, R. 2013. Digital Methods. Cambridge, MA: MIT Press.

Rogoff, B., Baker-Sennett, J., Lacasa, P. and Goldsmith, D. 1995. Development through Participation in Sociocultural Activity. In J. J. Goodnow, P. J. Miller and F. Kessel Eds. Cultural Practices as Contexts for Development. San Francisco, CA: Jossey-Bass: 45-66.

Ryan, M.-L. and Thon, J.-N. L. 2014. Storyworlds Across Media: Toward a MediaConscious Narratology. Lincoln, NE: University of Nebraska Press.

Salinger, A. 1995. In My Room: Teenagers in Their Bedrooms. San Francisco, CA: Chronicle Books.

Turkle, S. 1995. Life on the Screen: Identity in the Age of the Internet. New York: Simon \& Schuster.

Turkle, S. 2008. Always-On / Always-On-You: The Tethered Self. In J. E. Katz Ed. Handbook of Mobile Communication Studies. Cambridge, MA: MIT Press.

Turner, G. 2013. Understanding Celebrity. Thousand Oaks, CA: Sage.

\section{Interviews}

Ana, Elena, Dani. 2015. Interview by Pilar Lacasa, Madrid, Spain, 24 April. Lucia. 2015. Interview by Pilar Lacasa, Madrid, Spain, 19 May.

Luisa, Ana. 2015. Interview by Pilar Lacasa, Madrid, Spain, 8 February. 


\section{Appendix: Looking for Examples Through NVivo Nodes}

\begin{tabular}{|c|c|}
\hline NAME & DEFINITION \\
\hline \multicolumn{2}{|r|}{ BUILDING HEROES } \\
\hline Heroes & $\begin{array}{l}\text { How adolescents construct music heroes in the fan community, } \\
\text { which is organized around celebrities that in the fan community } \\
\text { can be seen as heroes. }\end{array}$ \\
\hline Activity and life & $\begin{array}{l}\text { Focuses on the daily life of the hero. Often related to the } \\
\text { information that the girls look up on the Internet. }\end{array}$ \\
\hline Stories & $\begin{array}{l}\text { These mainly arise from the fans reconstructing the lives of their } \\
\text { heroes through Wattpad. It also refers to micro-stories on Twitter. }\end{array}$ \\
\hline Information & $\begin{array}{l}\text { Information about the hero that they find on the Internet. For } \\
\text { example, what does he do in his everyday life? Where does he go? }\end{array}$ \\
\hline Material objects & $\begin{array}{l}\text { Material culture: for example, merchandise and other material } \\
\text { objects. }\end{array}$ \\
\hline Admiration & $\begin{array}{l}\text { This reflects attachment to the celebrity. It can occur in varying } \\
\text { degrees and includes emotional reactions. }\end{array}$ \\
\hline Online lives & $\begin{array}{l}\text { Environment generating a collective imagination that gives life to } \\
\text { the hero. Certain skills are required to engage in it. Refers mostly } \\
\text { to social networks. }\end{array}$ \\
\hline \multicolumn{2}{|r|}{ NETWORKED LIVES } \\
\hline Community & Common interests, being part of something. \\
\hline Languages & $\begin{array}{l}\text { Discourses related to specific practices. Used in a very general } \\
\text { sense. It can refer both to the discourse used in the fan } \\
\text { community, or to "marketing" purposes. }\end{array}$ \\
\hline On and offline & Somehow a relationship is established between the two worlds. \\
\hline Social networks & $\begin{array}{l}\text { These can become an instrument that determine activity in real } \\
\text { life. }\end{array}$ \\
\hline Risk & Comments about Internet safety. \\
\hline Followers - audience & $\begin{array}{l}\text { How and why this dimension is present in their use of social } \\
\text { networks. Includes references to "likes". }\end{array}$ \\
\hline Use - function & $\begin{array}{l}\text { This is a sub-category of social networks. Different social media } \\
\text { are used for different purposes. }\end{array}$ \\
\hline \multicolumn{2}{|r|}{ THE DILEMMA OF PUBLIC AND PRIVATE LIVES } \\
\hline Public - private & $\begin{array}{l}\text { The two mingle in the lives of adolescent girls. Private means } \\
\text { limitations are placed on the information that is available online. } \\
\text { We approached this interaction as a dynamic process present in } \\
\text { the construction of the identity/identities. }\end{array}$ \\
\hline Friendship & $\begin{array}{l}\text { This refers to a personal relationship between the fans, and can be } \\
\text { real or virtual. Also includes real friends, such as school friends or } \\
\text { neighbours. }\end{array}$ \\
\hline $\begin{array}{l}\text { Expression of one's } \\
\text { own identity }\end{array}$ & $\begin{array}{l}\text { This relates to the personal construction process in relation to the } \\
\text { fan community. }\end{array}$ \\
\hline Multiple accounts & $\begin{array}{l}\text { Explores the information posted via different accounts in specific } \\
\text { circumstances. }\end{array}$ \\
\hline Hide account & $\begin{array}{l}\text { An account can be public for strangers and hidden for closer } \\
\text { acquaintances (family or school friends). }\end{array}$ \\
\hline Hide identity & $\begin{array}{l}\text { This refers to avatars, for example, or the use of different names. A } \\
\text { profile may be public, but the fan hides his/her real name. }\end{array}$ \\
\hline
\end{tabular}

